\section{Use of Pneumococcal Vaccine}

To the Editor:-The otherwise excellent review of the outpatient diagnosis and management of chronic obstructive pulmonary disease (COPD) by Schapira and Reinke is marred by the author's equivocation regarding the use of pneumococcal vaccine. ${ }^{1}$ The authors cite the negative views of Hirschmann and Lipsky. ${ }^{2}$ A more recent meta-analysis of randomized controlled trials of pneumococcal vaccination has also cast doubt on its clinical effectiveness. ${ }^{3}$ In spite of these views, it is important for readers of the Journal to know that several casecontrol studies have demonstrated convincingly that vaccination is effective in preventing vaccine-type pneumococcal bacteremia. ${ }^{4}$ The clinical effectiveness of vaccination has also been demonstrated in an indirect cohort study by investigators at the Centers for Disease Control and Prevention. ${ }^{5}$ In their study, pneumococcal vaccination was $65 \%$ effective $(95 \%$ confidence interval $26 \%$ to $83 \%$ ) in preventing pneumococcal bacteremia in patients with COPD and asthma.

The reservations of some clinicians regarding the utility of pneumococcal vaccination for older patients may reflect the lack of evidence that vaccination prevents nonbacteremic pneumococcal pneumonia. Randomized controlled trials have thus far failed to provide such evidence, ${ }^{3}$ although methodologic problems, including the inadequate size of study populations, preclude drawing meaningful conclusions from these studies. ${ }^{6}$ There are many reasons to expect that pneumococcal vaccination should be effective in preventing nonbacteremic as well as bacteremic pneumococcal disease. However, even if vaccination prevents only pneumococcal bacteremia, preventing this disease alone is worthwhile, especially for patients with pulmonary disease.

The Advisory Committee on Immunization Practices and the American College of Physicians/Infectious Diseases Society of America Task Force on Adult Immunization are steadfast in recommending pneumococcal vaccination for patients with COPD and asthma. Readers of the Journal should not doubt this good advice. - David S. Fedson, MD, Harry T. Peters, Jr., Professor of Internal Medicine. University of Virginia School of Medicine, Charlottesville, VA 22908

\section{REFERENCES}

1. Schapira RM, Reinke LF. The outpatient diagnosis and management of chronic obstructive pulmonary disease. J Gen Intern Med. 1995:10:40-55.

2. Hirschmann JV, Lipsky BA. The pneumococcal vaccine after 15 years of use. Arch Intern Med. 1994:154:373-7.

3. Fine M, Smith MA, Carson CA. et al. Efficacy of pneumococcal vaccination in adults. A meta-analysis of randomized controlled trials. Arch Intern Med. 1994;154:2666-77.

4. Fedson DS, Shapiro ED, LaForce FM, et al. Pneumococcal vaccine after 15 years of use: another view. Arch Intern Med. 1994:154:25315.

5. Butler JC, Breiman RF, Campbell JF, Lipman HB, Broome CV, Facklam RR. Pneumococcal polysaccharide vaccine efficacy. An evaluation of current recommendations. JAMA. 1993;270: 1826-31.
6. Fedson DS. Pneumococcal vaccination in the prevention of community-acquired pneumonia: an optimistic view of cost-effectiveness. Semin Respir Infect. 1994:8:294-9.

In reply:-We thank Fedson for his comments in support of the administration of pneumococcal vaccination for patients with obstructive airways disease. Our personal practice is to offer pneumococcal vaccination to these patients. ${ }^{1}$ Some authorities have questioned the efficacy of pneumococcal vaccine. ${ }^{2}$ The vaccine is relatively inexpensive and is safe. Multiple issues regarding the use of pneumococcal vaccine remain unresolved, including its efficacy in preventing pneumonia without bacteremia, the populations in which the vaccine is most efficacious, the need for revaccination, and ways to ensure provision of the vaccination to high-risk patients. ${ }^{3}$ - RALPH $\mathbf{M}$. Schapira, MD, Assistant Professor of Medicine, Division of Pulmonary Medicine and Critical Care, The Medical College of Wisconsin, Zablocki VA Medical Center, Milwaukee, WI 53295: and LYNN F. ReINkx, RN, MSN, Pulmonary Clinical Nurse Specialist, Zablocki VA Medical Center, Milwaukee, WI

\section{REFERENCES}

1. Advisory Committee on Immunization Practices (ACIP). Update on adult immunization. MMWR 1991:40 (RR-12):1-94.

2. Hirschmann JV. Lipsky BA. The pneumococcal vaccine after 15 years of use. Arch Intern Med. 1994;154:373-7.

3. Wrenn $\mathrm{K}$, Zeldin M, Miller $O$. Influenza and pneumococcal vaccination in the emergency department: is it feasible? J Gen Intern Med. 1994; 9:425-9.

\section{Things That Ring in the Night}

To the Editor:-Peters'study of after-hours telephone calls ${ }^{1}$ provides additional insight into an important aspect of medical practice. Among the many reasons for the current lack of interest in primary care careers is the issue of lifestyle. Physicians in practice often identify after-hours phone calls as a negative lifestyle factor, yet the issue has been studied very little.

I wish to report additional data that complement Peters' article. One hundred consecutive after-hours phone calls in an academic general internal medicine practice were analyzed. The most common concern triggering a patient phone call was upper-respiratory infection symptoms $(18 \%)$, followed by medication questions or refills (12\%), gastrointestinal symptoms $(10 \%)$, and dyspnea (6\%). Drug-seeking behavior was noted in $5 \%$. Thirteen percent of calls resulted in the ordering of a prescription, $15 \%$ resulted in advice to go to an emergency department, and $65 \%$ resulted in no action being taken except giving advice and/or reassurance. Fifty percent of patient concerns had begun within the previous 24 hours, although $27 \%$ had been present for more than one week.

On-call physicians were asked to subjectively judge each 